\section{Experiência e Diversidade Marcam o Momento Brasileiro de Pesquisa em Tireóide}

Doi com grande prazer que aceitamos o convite para organizar uma Eedição especial dos Arquivos Brasileiros de Endocrinologia \& Metabologia dedicada à glândula tireóide, foco de interesse de vários grupos de pesquisa no Brasil. Esses grupos têm investigado diferentes aspectos moleculares, fisiológicos e clínicos da tireóide, com importantes contribuições científicas nessa área. Assim, em função da limitação de espaço, nosso primeiro desafio como Editores Convidados foi a seleção dos colaboradores e/ou temas que fariam parte dessa Edição. Considerando-se o grande número de grupos e espectro de tópicos que poderiam ser abordados, optamos pelo enfoque nos temas onde ocorreram as mais recentes e significativas contribuições "brasileiras" na pesquisa da glândula tireóide. Esperamos que esses artigos sejam de interesse não apenas dos leitores dos $\mathrm{ABE} \& \mathrm{M}$, mas que também contribuam para com o nível desta prestigiosa publicação que no momento encontra-se em processo de credenciamento para o MEDLINE/PubMed.

Desse modo, esta Edição contém 20 artigos autorados por 62 pesquisadores envolvidos na investigação de tópicos abrangendo praticamente todo o espectro da tireoidologia, representativos dos vários grupos de pesquisa no Brasil. Também estão incluídos nesta edição pesquisadores que trabalham fora do Brasil, mas que mantém fortes vínculos de colaboração e intercâmbio com grupos brasileiros.

$\mathrm{Na}$ organização das diferentes colaborações, achamos interessante que os artigos fossem agrupados sob grandes temas: (i) Aspectos funcionais e genéticos da glândula tireóide, (ii) Doença nodular, câncer e disfunções hormonais da tireóide, e (iii) Hormônios tireoideanos em outros sistemas.

$\mathrm{O}$ primeiro grupo de artigos traz de maneira bastante didática o que há de mais recente em termos de biologia celular e molecular de proteínaschave envolvidas no processo de biosíntese, metabolismo e ação dos hor mônios tireoideanos. Esse grupo de artigos também ilustra a íntima relação existente entre a pesquisa básica e clínica no campo da glândula tireóide. Vaisman et al (1) mostram a importância de se conhecer a fundo as enzimas envolvidas na organificação tireoideana do iodo para que se possa compreender os mecanismos adaptativos desencadeados durante carência alimentar de iodo (Knobel et al [2]) e identificar, tratar e prevenir o hipotiroidismo congênito, que é abordado por Perone et al (3) e Vono-Toniolo et al (4). Essa interação básico-clínica também fica evidente quando se estuda a metabolização e ação dos hormônios tireoideanos. Assim como o conhecimento da estrutura tridimensional dos receptores tireoideanos (Barra et al [5]) é fundamental para a compreensão da síndrome de resistência à esses hormônios (Carvalho et al [6]), o recente desenvolvimento de um modelo tridimensional expondo a semelhança existente entre as três desiodases proporciona nova vida à identificação e estudo das síndromes associadas a defeitos na ativação e inativação dos hormônios tireoideanos (Bianco [7]).

No segundo bloco, foram agrupados os artigos com enfoque nas manisfestações clínicas das principais doenças tireoidianas. A fisiopatologia, o diagnóstico e as diferentes opções terapêuticas da doença nodular

Arq Bras Endocrinol Metab vol 48 n 1 Fevereiro 2004 editorial

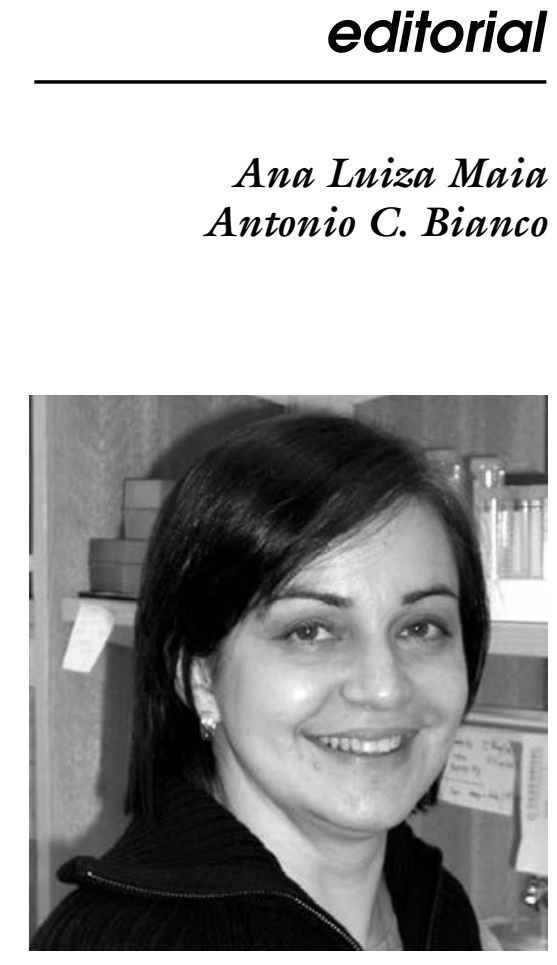

ALM é Professora Adjunta de Medicina, Serviço de Endocrinologia, Departamento de Medicina Interna, Faculdade de Medicina da Universidade Federal do Rio Grande do Sul e Visiting Associate Professor of Medicine, Division of Endocrinology, Diabetes and Hypertension, Brigham and Women's Hospital and Harvard Medical School.

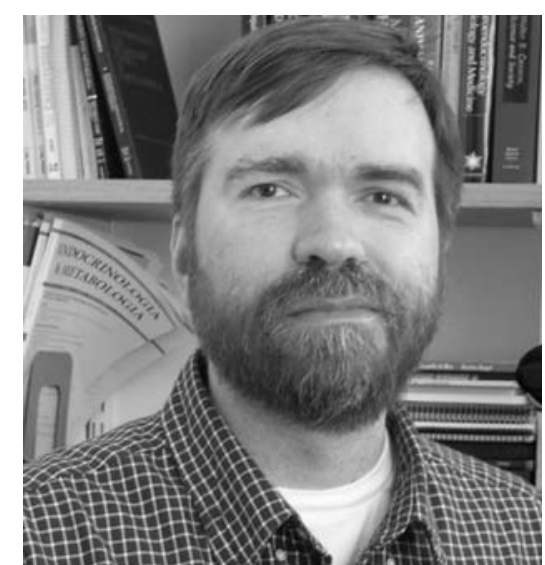

ACB é Associnte Professor of Medicine and ACB é Associate Professor of Medicine and Director of Research, Thyroid Section, Hospital and Harverd Medical School. Division of Endocrinology, Diabetes and 
benigna da tireóide são didaticamente abordados por Graf (8). Tomimori et al (9) apresentam os resultados de estudo no qual demonstram a importância da ultrasonografia tireoidiana como ferramenta no diagnóstico diferencial do nódulo benigno vs. maligno. A seguir, Matsuo et al (10) discutem o impacto dos novos conhecimentos proporcionados pela biologia molecular na identificação de possíveis marcadores biológicos assim como no entendimento do processo da transformação neoplásica da tireóide. Já, Ward \& Assumpção (11) descrevem as conseqüências da aplicação prática desses conhecimentos para o prognóstico e terapêutica dos pacientes com câncer diferenciado da tireóide. Os aspectos moleculares e oncológicos do carcinoma medular de tireóide são também discutidos em artigo de revisão (Puñales et al [12]).

No aspecto das disfunções hormonais, fica novamente evidente a importância do bom conhecimento da fisiologia para o entendimento das enfermidades tireoidianas. Nesse sentido, é interessante o artigo de Moura \& Moura (13) sobre a regulação da síntese e secreção do TSH, onde são discutidos os diferentes fatores que influenciam a concentração sérica desse importante regulador da função tireoidiana. Em relação às síndromes clínicas, destacamos as contribuições para o entendimento e abordagem terapêutica das denominadas disfunções tireoidianas mínimas, ou seja o hipotireoidismo e hipertireoidismo subclínico (Romaldini et al [14]), as controvérsias na utilização do iodo radioativo no tratamento da doença de Graves (Andrade et al [15]) e as peculiaridades da terapia dessa enfermidade em crianças e adolescentes (Monte et al [16]).

No último grupo de artigos, o enfoque é dado à interface dos hormônios tireoidianos com outros sistemas. O papel dos hormônios tireoideanos na sinalização adrenérgica no coração é abordado por Kim et al (17), enquanto em sentido oposto Pavan et al (18) discutem as disfunções tireoideanas induzidas pela amiodarona, droga amplamente utilizada no tratamento de arritmias cardiacas. Os efeitos moleculares e estruturais dos hormônios tireoidianos no esqueleto (Gouveia [19]) e a paralisia periódica hipocalêmica tireotóxica (Silva et al [20]), são os outros tópicos explorados neste bloco.

Finalizando, gostaríamos de agradecer a todos os colaboradores e em especial ao Editor-Chefe dos $\mathrm{ABE} \& M$, esta figura ímpar da Endocrinologia brasileira, nosso querido Claudio E. Kater, pela oportunidade de participarmos na elaboração desta Edição. Convidamos todos vocês para ler e apreciar essas importantes contribuições.

\section{REFERÊNCIAS}

1. Vaisman M, Rosenthal D, Carvalho DP. Enzimas envolvidas na organificação tireoidiana do iodo. Arq Bras Endocrinol Metab 2004;48/1:9-15.

2. Knobel $M$, Medeiros-Neto $G$. Moléstias associadas à carência crônica do iodo. Arq Bras Endocrinol Metab 2004;48/1:53-61.

3. Perone D, Teixeira SS, Clara SA, Santos DC, Nogueira CR. Aspectos genéticos do hipotireoidismo congênito. Arq Bras Endocrinol Metab 2004;48/1:62-69.

4. Vono-Toniolo J, Kopp P. Thyroglobulin gene mutations and other genetic defects associated with congenital hypothyroidism. Arq Bras Endocrinol Metab 2004;48/1:70-82.

5. Barra GB, Velasco LFR, Pessanha RP, Campos AM, Moura FN, Polikarpov I, et al. Mecanismo molecular da ação do hormônio tireoideano. Arq Bras Endocrinol Metab 2004;48/1:25-39.

6. Carvalho GA, Ramos HE. Síndrome de resistência ao hormônio tireoidiano. Arq Bras Endocrinol Metab 2004;48/1:83-92.

7. Bianco AC. Triplets! Unexpected structural similarity among the three enzymes that catalyze initiation and termination of thyroid hormone effects. Arq Bras Endocrinol Metab 2004;48/1:16-24.

8. Graf H. Doença nodular da tireóide. Arq Bras Endocrinol Metab 2004:48/1:93-104.

9. Tomimori EK, Bisi H, Medeiros-Neto G, Camargo RYA. Avaliação ultra-sonográfica dos nódulos tireóideos: Comparação com exame citológico e histopatológico. Arq Bras Éndocrinol Metab 2004;48/1:105-113.

10. Matsuo SE, Martins L, Leoni SG, Hajjar D, Ricarte-Filho JCM, Ebina KN, et al. Marcadores biológicos de tumores tiroidianos. Arq Bras Endocrinol Metab 2004;48/1:114-125.

11. Ward LS, Assumpção LVM. Cancer diferenciado da tiróide: Fatores prognósticos e tratamento. Arq Bras Endocrinol Metab 2004;48/1:126-136.

12. Puñales MK, Rocha AP, Gross JL, Maia AL. Carcinoma medular de tireóide: Aspectos moleculares, clínicooncológicos e terapêuticos. Arq Bras Endocrinol Metab 2004:48/1:137-146.

13. Moura EG, Moura CCP. Regulação da sintese e secreção de tireotrofina. Arq Bras Endocrinol Metab 2004;48/1:40-52.

14. Romaldini JH, Sgarbi JA, Farah CS. Disfunções mínimas da tiróide: Hipotiroidismo subclínico e hipertiroidismo subclínico. Arq Bras Endocrinol Metab 2004;48/1:147-158.

15. Andrade VA, Gross JL, Maia AL. lodo radioativo no manejo do hipertireoidismo da doença de Graves. Arq Bras Endocrinol Metab 2004;48/1:159-165.

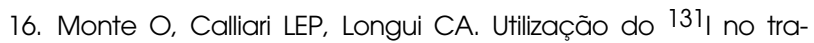
tamento da doença de Basedow Graves na infância e adolescência. Arq Bras Endocrinol Metab 2004;48/1:166-170.

17. Kim B, Carvalho-Bianco SD, Reed Larsen P. Thyroid hormone and adrenergic signaling in the heart. Arq Bras Endocrinol Metab 2004;48/1:171-175.

18. Pavan R, Jesus AMX, Maciel LMZ. A amiodarona e a tireóide. Arq Bras Endocrinol Metab 2004;48/1:176-182.

19. Gouveia CHA. O efeito molecular e estrutural do hormônio tiroideano no esqueleto. Arq Bras Endocrinol Metab 2004;48/1:183-195.

20. Silva MRD, Chiamolera MI, Kasamatsu TS, Cerutti JM, Maciel RMB. Paralisia periódica hipocalêmica tirotóxica, uma urgência endócrina: Revisão do quadro clínico e genético de 25 pacientes. Arq Bras Endocrinol Metab 2004;48/1:196-215. 